Fetal Diagnosis aud Therapy
Fetal Diagn Ther 2013;34:1-7

DOI: $10.1159 / 000350170$
Received: February 1, 2013

Accepted after revision: February 19, 2013

Published online: June 11, 2013

\title{
Impact of Maternal Obesity on Fetal Health
}

\author{
Kinneret Tenenbaum-Gavish Moshe Hod \\ Division of Maternal Fetal Medicine, Helen Schneider Hospital for Women, Rabin Medical Center, Sackler Faculty of \\ Medicine, Tel Aviv University, Petah-Tiqva, Israel
}

\section{Key Words}

Obesity · Fetal programming · Pregnancy complications . Congenital anomalies · Macrosomia $\cdot$ Childhood obesity

\begin{abstract}
The obesity epidemic is a problem of global importance with a profound impact on maternal-fetal health. Maternal overweight and obesity causes pregnancy complications such as gestational diabetes, hypertension and preeclampsia and affects fetal growth. Maternal obesity offers an altered genetic, hormonal and biochemical environment for the developing fetus/embryo and influences fetal growth and organ development. Offspring of obese mothers are subject to an increased risk of fetal demise, congenital anomalies and disrupted growth patterns, causing an increase in perinatal mortality. The impact of maternal obesity extends beyond intrauterine and neonatal life to childhood, adolescence and adulthood.

Copyright $\odot 2013$ S. Karger AG, Basel
\end{abstract}

The obesity epidemic is a problem of global importance with a profound impact on maternal-fetal health. It has reached a point at which $50 \%$ of women of childbearing age are either overweight (BMI 25-29.9) or obese (BMI $>30$ ) [1].Furthermore, $15-20 \%$ of women starting pregnancy are obese $[2,3]$, and $20-40 \%$ of pregnant women suffer from excessive weight gain during pregnancy [4].

\section{KARGER}

E-Mail karger@karger.com www.karger.com/fdt
Maternal obesity is an obstetric risk factor because of its potential consequences for mother and offspring. Maternal overweight and obesity causes pregnancy complications such as gestational diabetes, hypertension and preeclampsia and affects fetal growth. As a result of increased complication rate, more than $50 \%$ of mortality cases during pregnancy, childbirth or the puerperium are of women who are either obese or overweight [4].

Obesity is also associated with a marked increase in fetal/neonatal complications including stillbirths [5], neonatal deaths, neonatal intensive care unit admission, preterm births, and congenital abnormalities [6]. Offspring of obese mothers are also subject to disrupted growth patterns (both growth restriction and overgrowth). Increased fetal weight and adiposity at birth increases macrosomia and difficulties associated with delivery of large-for-gestational-age infants. It has also longterm effects on neonatal, childhood and adult health.

\section{Mechanism of Action of Obesity on Fetal Growth}

Maternal obesity impacts the growing fetus/embryo by way of several pathways: genetic, environmental and the diverse network of interactions between them. The exact mechanism in which obesity mediates poor health outcomes for both mother and fetus, are far from clear. Pieces of the puzzle are placed together incorporating knowl- 
edge gathered from epidemiological studies, experiments on animals and placenta models.

The embryo inherits a given set of genes from both parents. It draws upon this genetic milieu for its continued development and growth. Genome-wide association studies have identified several common genetic variants associated with high adiposity and obesity, each with weak effects [7]. Some of the candidate genes mentioned are those of insulin, insulin-like growth factor and their receptors because these hormones are known to influence fetal growth and body composition [8]. The genetic influence of maternal obesity on the developing child cannot be explained by Mendelian-model inheritance of a given set of genes alone. Children of obese mothers are more at risk of overweight or obesity than those of obese fathers [9]. This illustrates the pivotal role of intrauterine conditions on susceptibility to obesity, type 2 diabetes, and cardiovascular disease in the offspring. Epigenetic processes have a crucial role in determining fetal, neonatal and adult health.

The developing fetus depends upon a complex feto-maternal interaction. This intricate interaction relies on several components: maternal nutritional intake, placental transfer mechanisms and uterine blood supply, which depend on maternal metabolic and cardiovascular condition.

Glucose was considered the main metabolite that transmits the effect of obesity to the developing fetus. The obese population suffers from elevated blood glucose levels, insulin resistance and high rates of overt diabetes. Obese women are characterized by a significantly higher postprandial glucose peak value, increased 1- and 2-hour postprandial glucose levels, increased time interval for glucose peak, and significantly lower mean blood glucose during the night [10]. Maternal hyperglycemia during pregnancy was thought to be one of the most important predictive factors of pregnancy complications in the obese population. It is now recognized that other maternal parameters associated with obesity and/or overnutrition during pregnancy are also involved including hyperglycemia and hypertriglyceridemia. The altered endocrine milieu associated with obesity (increased levels of insulin, androgens, and leptin) [11] is also associated with a number of maternal metabolic disturbances such as insulin resistance, diabetes and increased blood pressure [12] all of which influence fetal well-being.

Obesity is associated with a chronic state of inflammation $[13,14]$ and alternation in the homeostasis of cytokines and adipokines. Adipose tissue is an active endocrine organ and a source of proinflammatory cytokines (adipokines) such as adiponectin. Adiponectin is deemed important in promoting insulin sensitivity and stimulat- ing glucose uptake in skeletal muscle. In pregnancy, it influences placental transfer of nutrients and placental insulin-stimulated amino acid uptake. Pregnant women suffering from obesity demonstrate low circulating levels of adiponectin. Low levels of adiponectin are associated with increased fetal growth [15]. Furthermore, in animal models, adiponectin administration causes downregulation of activity and expression of key placental nutrient transporters. Adiponectin also binds to the adiponectin receptor-2 on the trophoblast cell and activates p38 MAPK and PPAR- $\alpha$, which inhibits the insulin/IGF-1 signaling pathway. Therefore, it is not surprising that maternal serum adiponectin is inversely correlated to fetal growth throughout the full range of birth weights.

Individuals inflicted by obesity demonstrate high plasma levels of glucose and free fatty acids. The 'accelerated starvation' of pregnancy (meaning the increase in ketosis observed in pregnant women) is responsible for the decrease in insulin's ability to suppress lipolysis in pregnant women. This causes a further two- to threefold increase in the blood levels of cholesterol and free fatty acids with advancing gestation [16]. Maternal high levels of triglycerides (which are not readily transferred across the placenta) alternate placental lipases activity and increase placental transfer of metabolites which are stored as fetal fat deposits [17]. Oxidized lipids can be cytotoxic and influence gene expression by acting as ligands for nuclear receptors [18]. They may also affect antenatal organ development and impact postnatal response to environmental stimuli. Furthermore, intrauterine exposure to high lipid levels, which act as both transcriptional activators and signaling molecules, may cause epigenetic changes in lipid sensing and metabolism genes [19]. This may mediate epigenetic changes in the offspring of obese mothers that induce obesity in the offspring.

Obesity has also been associated with tissue-specific changes in mitochondrial function and elevated production of reactive oxygen species leading to increased oxidative stress [20]. The combination of excess fatty acids and oxidative stress leads to the production of oxidized lipids. Oxidized lipids can inhibit trophoblast invasion and influence placental development, lipid metabolism and lipid transport [18] - which may explain some of the adverse pregnancy outcomes related to obesity such as preeclampsia.

Other changes associated with maternal obesity may also lead to alterations in placental development or function. For example, maternal obesity is associated with a reduction in placental villous proliferation and apoptosis which may increase susceptibility to adverse pregnancy 
outcomes [21]. Animal models suggest that a lifelong high-fat diet results in altered placental vascularization which causes an increase in placental hypoxia and oxidative stress. In this model, the consequences of such placental changes were an increase in stillbirths, and a decrease of birth weight and in neonatal survival [22]. Epidemiologic studies also demonstrated a correlation between maternal metabolic syndrome and placental dysfunction [23].

Serum concentrations of leptin are positively associated with body fat stores [24]. Maternal obesity is accompanied by maternal hyperleptinemia and placental leptin resistance contributing to alternations in placental function and amino acid transfer [25]. Amino acids also stimulate insulin secretion so an increase in amino acid trans-placental transfer contributes to fetal hyperinsulinemic state. IGF-1:IGFBP3 ratio and leptin levels are higher in cord blood of large-for-date fetuses. Higher IGF-1:IGFBP3 ratio may indicate a greater amount of unbound IGF-1 causing increased fetal growth [26]. These are some examples for processes which act in league to cause a net increase in available energy and 'building blocks' to the fetus and this combined with the hyperinsulinemic state may explain the increase in large-for-gestational-age infants seen in obese women. There is some evidence to suggest that maternal obesity also influences the in utero environment by altering the regulation of appetite, satiety, and adipocyte maturation in the fetus [27]. Offspring of rats that were fed high-fat diets during pregnancy exhibit postnatal hyperphagia [28]. These offspring also continued to consume more and maintain higher body weights than controls, thus maintaining their 'obese phenotype'.

Thus, the malevolent effect of obesity on embryonic/ fetal growth and development is profound and apparent throughout pregnancy.

\section{Early Pregnancy}

Metwally et al. [29], in a meta-analysis including 12 studies, found that women with $\mathrm{BMI} \geq 30$ were at increased risk of miscarriage compared to women with normal BMI [odds ratio (OR), 1.89; 95\% confidence interval (CI), 1.14-3.13]. This excess risk of miscarriage in the overweight and obese population is not explained by an increase of embryonic aneuploidy [30]. Obesity may increase early pregnancy-loss rate in a mechanism that is not dependent upon oocyte or ovarian function but rather endometrial or placental. Bellver et al. [31] demonstrated that obese and overweight women receiving oocyte dona-

Impact of Maternal Obesity on Fetal Health tion did not differ from non-obese women in implantation and pregnancy rates, but showed a decrease in ongoing-pregnancy rate related to BMI. An unfavorable hormonal environment characteristic of maternal obesity combined with the chronic inflammatory state associated with excess adipose tissue may be the underlying mechanism. Observational data [32] suggest that weight reduction may reduce miscarriage rate in obese population.

Maternal obesity is also associated with an increased risk of dizygotic twinning. Reddy et al. [33] conducted an analysis of 51,783 pregnancies (561 twin) in the Collaborative Perinatal Project. They found that the incidence of dizygotic twins in women with BMI $\geq 30$ was $1.1 \%$ compared to $0.5 \%$ in women whose BMI was $<25$. Others [34] also found an increased incidence of dizygotic, but not monozygotic, twin gestation in the obese population. There is very little data specifically concerning twin pregnancy outcome in the obese population. It is beyond the scope of this review to discuss the full complexity and challenge in following twin pregnancies in general and in the obese population in particular. It is sufficient to mention the excess risk of pregnancy complication associated with twin pregnancy including preterm birth, preeclampsia, diabetes and fetal growth disturbances. It is also of importance to briefly mention that in obese gravitae, the estimation of fetal weight, especially for the second twin, has been shown to be decreased in accuracy, which may mislead clinical judgment when considering timing and mode of delivery [35].

\section{Congenital Anomalies}

Good ultrasound imaging of the fetus is more difficult in obese gravidae compared to normal-weight women [36-38]. As a result, the antenatal detection rate for congenital anomalies is lower in obese women, resulting in fewer antepartum diagnoses and more affected liveborns and stillborns among births to obese mothers. For example, the analysis of data collected in the FaSTER study indicates that the performance of second-trimester genetic sonography is influenced by obesity, with a significantly higher missed diagnosis rate for multiple minor markers and lower likelihood for detecting common anomalies in the obese population [38].

Furthermore, some congenital anomalies are more prevalent in the offspring of obese mothers. The increase in the absolute rate of specific congenital anomalies is increased with increasing maternal weight. Stothard et al. [39] reviewed 39 observational studies and 18 meta-analyses. They calculated pooled ORs for specific anomalies 
in the obese population. Compared with mothers of normal BMI, obese mothers were at increased odds of pregnancies affected by neural tube defects (NTD) (OR, 1.87; 95\% CI, 1.62-2.15), spina bifida (OR, 2.24; 95\% CI, 1.862.69), cardiovascular anomalies (OR, 1.30; 95\% CI, 1.121.51), septal anomalies (OR, 1.20; 95\% CI, 1.09-1.31), cleft palate (OR, 1.23; 95\% CI, 1.03-1.47), cleft lip and palate $(\mathrm{OR}, 1.20 ; 95 \% \mathrm{CI}, 1.03-1.40)$, anorectal atresia (OR, 1.48; 95\% CI, 1.12-1.97), hydrocephaly (OR, 1.68; 95\% CI, 1.19-2.36), and limb reduction anomalies (OR, 1.34; 95\% CI, 1.03-1.73). The risk of gastroschisis among obese mothers was significantly reduced (OR, $0.17 ; 95 \%$ CI, 0.10-0.30).

Another meta-analysis reviewed the risk for NTDs in pregnancies of obese mothers [40]. The OR for NTD was 1.22 (95\% CI, 0.99-1.49) for overweight mothers, 1.70 (95\% CI, 1.34-2.15) for obese women, and 3.11 (95\% CI, 1.75-5.46) among severely obese women, compared with normal-weight women. This risk of NTDs increases with increasing pre-pregnancy weight and may not be ameliorated by increase in folate intake [41].

Maternal obesity adversely affects trans-abdominal ultrasound imaging of fetal anatomy during the second trimester. There is little to be done to technically improve the image obtained. Delaying, repeating, or increasing the duration of the examination may only partially, if at all, mitigate the technical limitations that obesity imposes on visualization [42]. In the general population, several studies have demonstrated the efficacy of late firstor early second-trimester anatomy scans $[43,44]$. In the obese population early fetal anatomic assessment by trans-vaginal ultrasound may provide an alternative and more satisfactory window for better evaluating fetal anatomy [45].

\section{Labor and Delivery}

\section{Onset of Delivery}

Obesity is not inherently associated with an increased risk of spontaneous preterm birth. A meta-analysis [46] including 39 studies found that after adjustment for confounders, the risk for spontaneous preterm birth (sPTB) in the obese and overweight population was actually reduced (adjusted OR, 0.87; 95\% CI, 0.74-1.04). Others [47] also found a reduced risk of sPTB in pregnancies complicated by obesity and even found that obese/overweight women exhibit less uterine activity than normal/ underweight women [48]. Although the risk for spontaneous preterm birth is not increased in obese women, the overall rate of preterm delivery may be increased. The increase in preterm deliveries in the obese population is not related to an innate part of pregnancy course but rather a measure of obesity-related medical and antenatal complications and is increased as BMI rises [46, 49]. Furthermore, maternal obesity is related to prolongation of pregnancy (i.e. postterm pregnancy). The explanation for this is yet to be puzzled out. Stotland et al. [50] found that higher pre-pregnancy BMI was associated with higher risk of progressing past 40 weeks (adjusted OR, 1.69; 95\% CI, 1.23-2.31 for reaching 42 weeks' gestation). There is an inverse relationship between BMI and the likelihood of spontaneous onset of labor at term, and higher rates of postdate pregnancy in women who were already obese during first trimester or had excess weight gain during pregnancy [51].

\section{Macrosomia and Birth Trauma}

The relationship between maternal weight, weight gain during pregnancy and fetal/neonatal birth weight is well documented [52-55]. Studies investigating the relationship between maternal obesity and fetal growth have shown that obese women have an 18-26\% increased chance of delivering large-for-date infants, even after controlling for maternal diabetes [56].

The metabolic (environmentally induced) macrosomia, as opposed to constitutional macrosomia, is characterized by excessive fat accumulation and fetal hyperinsulinemia during fetal life which results in growth of a fetus beyond its genetic potential. Infants above the 97th birth weight percentile have a $2-3$-fold higher risk of unexplained intrauterine fetal death [57]. Excessive fetal growth carries significant perinatal morbidities although an exact estimation of their prevalence in the obese population is lacking. Macrosomic infants of obese mothers have an increased likelihood of operative delivery, shoulder dystocia, and brachial plexus injury [58, 59]. Larger fetuses also run a higher risk of fetal hypoxemia and shoulder dystocia especially for those above 4,500 g [60]. Lewis et al. [61] tried to prospectively evaluate risk factors for shoulder dystocia. They found that $32 \%$ of cases occurred to obese ( $>90 \mathrm{~kg}$ ) women and $25 \%$ of women experiencing shoulder dystocia had excessive maternal weight gain ( $>20 \mathrm{~kg}$ ). Others [62] found that $5 \%$ of extremely obese (over 250 pounds) women were found to have experienced shoulder dystocia. For obese non-diabetic women carrying fetuses whose weights were estimated to be within normal limits, there was no increased risk of shoulder dystocia [63]. The issue is further complicated by the decreased ability to accurately estimate fe-
Tenenbaum-Gavish/Hod 
tal weight at the upper extremes of the growth curve, with errors exceeding $10 \%$ of the birth weight, in particular on the basis of suboptimal visualization $[64,35]$. This compromises the clinicians' ability to counsel obese patients about labor-related issues such as the preferred mode of delivery.

Neonates born to obese women have a higher rate of low Apgar score than those of normal-weight women [47, $65,66]$. In view of the aforementioned higher rate of labor-related complications, it is not surprising that, after delivery, newborns of obese mothers show an increase in neonatal admissions to neonatal intensive care units with complications such as neonatal trauma and incubator requirement [67]. Maternal obesity is associated with increased overall risk of infant death, mainly neonatal deaths related to pregnancy complications or preterm birth [68].

A meta-analysis including 9 studies by $\mathrm{Chu}$ et al. [69], described an increased risk of stillbirth in the obese population. OR for stillbirth was 1.47 (95\% CI, 1.08-1.94) for overweight women and 2.07 (95\% CI, 1.59-2.74) for obese pregnant women, compared with normal-weight pregnant women. The increase in stillbirth rate in obese women is presumed to occur due to the accelerated fetal growth induced by the fetal hyperinsulinemia and excess nutrient 'influx', in combination with uteroplacental insufficiency, which may lead to fetal hypoxia and death.

Maternal overweight and obesity are the most important potentially modifiable risk factors for stillbirth in high-income country settings. The number of stillbirths attributed to obesity across high-income countries is in the vicinity of 8,064 each year [70]. Implementation of preconception care, routine weighing at first antenatal visit, individualized pregnancy care plan, including dietician counseling (exercise and diet), could potentially reduce these risk factors [71].

\section{Life-Long Impact}

Later in life, there is an inverse relationship between birth weight and health at both ends of the birth weight curve. Excessive maternal body weight or weight gain during pregnancy disrupts intrauterine environment and brings about permanent changes in the hypothalamus, pancreatic islet cells, adipose tissue and other body weight-regulating mechanisms of the offspring. Maternal pre-pregnancy overweight has been found to be an independent risk factor for infant and adolescence overweight and abdominal obesity [72]. Whitaker et al. [73] described a retrospective cohort study of 8,400 children, who were born to obese mothers (based on BMI in the first trimester). These children had a double rate of obesity at age 2 years. The prevalence of childhood obesity (BMI $>95$ th percentile) in children of women with BMI $>30$, at ages 2,3 , and 4 years was $15.1,20.6$, and $24.1 \%$, respectively. The infants who were overweight at 3-5 years of age were 4.1-7.9 times more likely to be obese in young adulthood. Hence, fetal overnutrition during pregnancy carries an increased risk of various ailments later in life such as obesity, hypertension, diabetes, etc. [74]. Several studies have found that infants born at the highest end of the distribution curve for weight were at a higher risk of being obese in childhood, adolescence and adulthood when compared with normal-sized infants $[75,76]$.

Some studies also suggest that children exposed to pregnancies complicated by metabolic conditions, such as diabetes, hypertension, and obesity, showed an increased risk of neurodevelopmental disorders, autism spectrum disorders and developmental delay [77], although interpretation of data is limited by lack of information on potential confounders.

Maternal overnutrition and/or obesity during pregnancy afflict upon the developing child a fate of later-life overweight, thus creating a vicious cycle of epidemic scale. However, this mechanism is not a 'perpetuum mobile'. Obese women and health care providers have it within their power to reverse the tide on the obesity epidemic. Dietary restriction and weight loss prior to pregnancy are proven strategies to improve infant health outcome. Pregnancies after bariatric surgery are less likely to be complicated by gestational diabetes mellitus, hypertension, preeclampsia, and macrosomia than are pregnancies of obese women who have not undergone such surgery [78-80]. Bariatric surgery prior to a planned pregnancy is the best strategy for reducing obesity-related complication for mother and child. In unplanned pregnancies, controlled or minimal weight gain during pregnancy may also mitigate the impact of obesity and produce a dramatic positive impact on pregnancy outcome. Pregnancy also provides a 'window of opportunity' in which obese women are more susceptible for lifestyle interventions such as diet and exercise counseling, thus allowing health care givers to intervene. 


\section{References}

$>1$ Kanagalingam MG, Forouhi NG, Greer IA, 16 Catalano PM: Obesity, insulin resistance, and Sattar N: Changes in booking body mass over a decade: retrospective analysis from a Glasgow Maternity Hospital. BJOG 2005;112: 1431-1433.

2 Heslehurst N, Ells LJ, Simpson H, Batterham A, Wilkinson J: Trends in maternal obesity incidence rates, demographic predictors, and health inequalities in 36,821 women over a 15-year period. BJOG 2007;114:187-194.

$>3$ Willis K, Sheiner E: Bariatric surgery and pregnancy: the magical solution? J Perinat Med 2012;8:1-8.

4 Thangaratinam S, Rogozińska E, Jolly K, Glinkowski S, Duda W, Borowiack E, Coomarasamy $A$, Khan KS: Interventions to reduce or prevent obesity in pregnant women: a systematic review. Health Technol Assess 2012 16:iii-iv, 1-191.

5 Froen JF, Arnestad M, Frey K, Vege A, Saugstad OD: Risk factors for sudden intrauterine unexplained death: epidemiologic characteristics of singleton cases in Oslo, Norway, 1986-1995. Am J Obstet Gynecol 2001;184: 694-702.

6 Ramachenderan J, Bradford J, McLean J: Maternal obesity and pregnancy complications: a review. Aust NZ J Obstet Gynaecol 2008;48: 228-245.

7 Han JC, Lawlor DA, Kimm SY: Childhood obesity. Lancet 2010;375:1737-1748.

$>8$ Henriksen T: The macrosomic fetus: a challenge in current obstetrics. Acta Obstet Gynecol Scand 2008;87:134-145.

$>9$ Whitaker KL, Jarvis MJ, Beeken RJ, Boniface $\mathrm{D}$, Wardle J: Comparing maternal and paternal intergenerational transmission of obesity risk in a large population-based sample. Am J Clin Nutr 2010;91:1560-1567.

-10 Yogev Y, Ben-Haroush A, Chen R, Rosenn B, Hod M, Langer O: Diurnal glycemic profile in obese and normal weight nondiabetic pregnant women. Am J Obstet Gynecol 2004;191: 949-953.

11 Practice Committee of American Society for Reproductive Medicine: Obesity and reproduction: an educational bulletin. Fertil Steril 2008;90:S21-S29.

-12 Hajer GR, van Haeften TW, Visseren FL: Adipose tissue dysfunction in obesity, diabetes, and vascular diseases. Eur Heart J 2008;29: 2959-2971.

13 Schmatz M, Madan J, Marino T, Davis J: Maternal obesity: the interplay between inflammation, mother and fetus. J Perinatol 2010;30: 441-446.

-14 Fujita K, Nishizawa H, Funahashi T, Shimomura I, Shimabukuro M: Systemic oxidative stress is associated with visceral fat accumulation and the metabolic syndrome. Circ J 2006; 70:1437-1442.

15 Aye IL, Powell TL, Jansson T: Review: Adiponectin - The missing link between maternal adiposity, placental transport and fetal growth? Placenta 2013;34(suppl):S40-S45. pregnancy outcome. Reproduction 2010;140 365-371.

17 Herrera E, Amusquivar E: Lipid metabolism in the fetus and the newborn. Diabetes Metab Res Rev 2000;16:202-210.

18 Jarvie E, Hauguel-de-Mouzon S, Nelson SM, Sattar N, Catalano PM, Freeman DJ: Lipotoxicity in obese pregnancy and its potential role in adverse pregnancy outcome and obesity in the offspring. Clin Sci (Lond) 2010;119:123129.

19 Heerwagen MJ, Miller MR, Barbour LA, Friedman JE: Maternal obesity and fetal metabolic programming: a fertile epigenetic soil. Am J Physiol Regul Integr Comp Physio 2010;299:R711-R722.

-20 Furukawa S, Fujita T, Shimabukuro M, Iwaki $\mathrm{M}$, Yamada Y: Increased oxidative stress in obesity and its impact on metabolic syndrome. J Clin Invest 2004;114:1752-1761.

21 Higgins L, Mills TA, Greenwood SL, Cowley EJ, Sibley CP, Jones RL: Maternal obesity and its effect on placental cell turnover. J Matern Fetal Neonatal Med 2013, E-pub ahead of print.

22 Hayes EK, Lechowicz A, Petrik JJ, Storozhuk Y, Paez-Parent S: Adverse Fetal and Neonatal Outcomes Associated with a Life-Long High Fat Diet: Role of Altered Development of the Placental Vasculature. PLoS One 2012; 7:e33370

23 Ray JG, Vermeulen MJ, Schull MJ, McDonald S, Redelmeier DA: Metabolic syndrome and the risk of placental dysfunction. J Obstet Gynaecol Can 2005;27:1095-1101.

24 Moyer-Mileur LJ, Slater H, Thomson JA, Mihalopoulos N, Byrne J, Varner MW: Newborn Adiposity Measured by Plethysmography Is Not Predicted by Late Gestation Two-Dimensional Ultrasound Measures of Fetal Growth. J Nutr 2009;139:1772-1778.

25 Farley DM, Choi J, Dudley DJ, Li C, Jenkins SL, Myatt L, Nathanielsz PW: Placental amino acid transport and placental leptin resistance in pregnancies complicated by maternal obesity. Placenta 2010;31:718-724.

26 Moyer-Mileur LJ, Slater H, Thomson JA, Mihalopoulos N, Byrne J, Varner MW: Newborn Adiposity Measured by Plethysmography Is Not Predicted by Late Gestation Two-Dimensional Ultrasound Measures of Fetal Growth. J Nutr 2009;139:1772-1778.

27 Olson G: Obesity and implications for future generations. Am J Obstet Gynecol 2012;206: 255-257.

28 Muhlhausler B, Ong Z: The fetal origins of obesity: early origins of altered food intake. Endocr Metab Immune Disord Drug Targets 2011;11:189-197.

29 Metwally M, Ong KJ, Ledger WL, Li TC: Does high body mass index increase the risk of miscarriage after spontaneous and assisted conception? A meta-analysis of the evidence. Fertil Steril 2008;90:714-726.
30 Landres IV, Milki AA, Lathi RB: Karyotype of miscarriages in relation to maternal weight. Hum Reprod 2010;25:1123-1126.

31 Bellver J, Melo MA, Bosch E, Serra V, Remohí J, Pellicer A: Obesity and poor reproductive outcome: the potential role of the endometrium. Fertil Steril 2007;88:446-451.

32 Clark AM, Thornley B, Tomlinson L, Galletley C, Norman RJ: Weight loss in obese infertile women results in improvement in reproductive outcome for all forms of fertility treatment. Hum Reprod 1998;13:1502-1505.

33 Reddy UM, Branum AM, Klebanoff MA: Relationship of mass index and height to twinning. Obstet Gynecol 2005;105:593-597.

34 Naeye RL: Maternal body weight and pregnancy outcome. Am J Clin Nutr 1990;52:273279.

35 Maxwell C, Glanc P: Imaging and obesity: a perspective during pregnancy AJR Am J Roentgenol 2011;196:311-319.

$>36$ Hendler I, Blackwell SC, Bujold E, Treadwell MC, Wolfe HM, Sokol RJ, Sorokin Y: The impact of maternal obesity on midtrimester sonographic visualization of fetal cardiac and craniospinal structures. Int J Obes Relat Metab Disord 2004;28:1607-1611.

37 Dashe JS, McIntire DD, Twickler DM: Effect of maternal obesity on the ultrasound detection of anomalous fetuses. Obstet Gynecol 2009;113:1001-1007.

-38 Aagaard-Tillery KM, Flint Porter T, Malone FD, Nyberg DA, Collins J, Comstock CH, Hankins G, Eddleman K, Dugoff L, Wolfe HM, D'Alton ME: Influence of maternal BMI on genetic sonography in the FaSTER trial. Prenat Diagn 2010;30:14-22.

39 Stothard KJ, Tennant PW, Bell R, Rankin J: Maternal overweight and obesity and the risk of congenital anomalies: a systematic review and meta-analysis. JAMA 2009;301:636-650.

40 Rasmussen SA, Chu SY, Kim SY, Schmid CH Lau J: Maternal obesity and risk of neural tube defects: a metaanalysis. Am J Obstet Gynecol 2008;198:611-619.

41 Werler MM, Louik C, Shapiro S, Mitchell AA Prepregnant weight in relation to risk of neural tube defects. JAMA 1996;275:1089-1092.

42 Hendler I, Blackwell SC, Bujold E, et al: The impact of maternal obesity on midtrimester sonographic visualization of fetal cardiac and craniospinal structures. Int J Obes Relat Metab Disord 2004;28:1607-1611.

43 Timor-Tritsch IE, Fuchs KM, Monteagudo A, D'alton ME: Performing a fetal anatomy scan at the time of first-trimester screening. Obstet Gynecol 2009;113:402-407.

44 Yagel S, Cohen SM, Messing B: First and early second trimester fetal heart screening. Curr Opin Obstet Gynecol 2007;19:183-190.

45 Maxwell C, Glanc P: Imaging and obesity: a perspective during pregnancy. AJR Am J Roentgenol 2011;196:311-319. 
-46 Torloni MR, Betrán AP, Daher S, Widmer M, Dolan SM, Menon R, Bergel E, Allen T, Merialdi M: Maternal BMI and preterm birth: a systematic review of the literature with metaanalysis. J Matern Fetal Neonatal Med 2009; 22:957-970.

-47 Sebire NJ, Jolly M, Harris JP, Wadsworth J, Joffe M, Beard RW, Regan L, Robinson S: Maternal obesity and pregnancy outcome: a study of 287,213 pregnancies in London. Int J Obes Relat Metab Disord 2001;25:1175-1182.

48 Ehrenberg HM, Iams JD, Goldenberg RL, Newman RB, Weiner SJ, Sibai BM, Caritis SN, Miodovnik M, Dombrowski MP; Eunice Kennedy Shriver National Institute of Child Health and Human Development (NICHD) Maternal-Fetal Medicine Units Network (MFMU): Maternal obesity, uterine activity, and the risk of spontaneous preterm birth. Obstet Gynecol 2009;113:48-52.

49 Baeten JM, Bukusi EA, Lambe M: Pregnancy complications and outcomes among overweight and obese nulliparous women. Am J Public Health 2001;91:436-440.

50 Stotland NE, Washington AE, Caughey A: Prepregnancy body mass index and the length of gestation at term. Am J Obstet Gynecol 2007;197:378.e1-e5.

51 Denison FC, Price J, Graham C, Wild S, Liston WA: Maternal obesity, length of gestation, risk of postdates pregnancy and spontaneous onset of labour at term. BJOG 2008; 115:720-725.

52 Abrams BF, Laros RK Jr: Prepregnancy weight, weight gain, and birth weight. Am J Obstet Gynecol 1986;154:503-509.

53 Frentzen B, Dimperio D, Cruz A: Maternal weight gain: effect on infant birth weight among overweight and average-weight lowincome women. Am J Obstet Gynecol 1988; 159:1114-1117.

54 Johnson JW, Longmate JA, Frentzen B: Excessive maternal weight and pregnancy outcome. Am J Obstet Gynecol 1992;167:353370.

55 Mahony R, Foley M, McAuliffe F, O’Herlihy C: Maternal weight characteristics influence recurrence of fetal macrosomia in women with normal glucose tolerance. Aust NZ J Obstet Gynaecol 2007;47:399-401.

56 Bhattacharya S, Campbell DM, Liston WA, Bhattacharya S: Effect of Body Mass Index on pregnancy outcomes in nulliparous women delivering singleton babies. BMC Public Health 2007;7:168.
Rasmussen S, Albrechtsen S, Irgens LM, Dalaker, Maartmann-Moe H, Vlatkovic L, et al: Risk factors for unexplained antepartum fetal death in Norway 1967-1998. Early Hum Dev 2003;71:39-52.

58 American College of Obstetricians and Gynecologists (ACOG): Fetal macrosomia. Washington, DC, 2000. ACOG practice bulletin; no. 22 .

59 Ecker JL, Greenberg JA, Norwitz ER, Nadel AS, Repke JT: Birth weight as a predictor of brachial plexus injury. Obstet Gynecol 1997; 89:643-647.

60 Henriksen T: The macrosomic fetus: a challenge in current obstetrics. Acta Obstet Gynecol Scand 2008;87:134-145.

61 Lewis DF, Edwards MS, Asrat T, Adair CD, Brooks G, London S: Can shoulder dystocia be predicted? Preconceptual and prenatal factors. J Reprod Med 1998;43:654-658.

62 Hassan AA: Shoulder dystocia: risk factors and prevention. Aust NZ J Obstet Gynaecol 1988;28:107-109.

63 Robinson H, Tkatsch S, Mayes DC, Bott N, Okun N: Is maternal obesity a predictor of shoulder dystocia? Obstet Gynecol 2003;101: 24-27.

64 Surkan PJ, Hsieh CC, Johansson AL, Dickman PW, Cnattingius S: Reasons for increasing trends in large for gestational age births. Obstet Gynecol 2004;104:720-726.

65 Nohr EA, Timpson NJ, Andersen CS, Davey Smith G, Olsen J, Sorensen TI: Severe obesity in young women and reproductive health: the Danish National Birth Cohort. PLoS One 2009; 4:e8444.

66 Ovesen, P, Rasmussen S, Kesmodel U: Effect of Prepregnancy Maternal Overweight and Obesity on Pregnancy Outcome. Obstet Gynecol 2011;118:305-312.

67 Usha Kiran TS, Hemmadi S, Bethel J, Evans J: Outcome of pregnancy in a woman with an increased body mass index. BJOG 2005;112: 768-772.

68 Chen A, Feresu SA, Fernandez C, Rogan WJ: Maternal obesity and the risk of infant death in the United States. Epidemiology 2009;20: $74-81$.
69 Chu SY, Kim SY, Lau J, Schmid CH, Dietz PM, Callaghan WM, Curtis KM: Maternal obesity and risk of stillbirth: a metaanalysis. Am J Obstet Gynecol 2007; 197:223.

70 Flenady V, Koopmans L, Middleton P, Frøen JF, Smith GC, Gibbons K, Coory M, Gordon A, Ellwood D, McIntyre HD, Fretts R, Ezzati M: Major risk factors for stillbirth in high-income countries: a systematic review and meta-analysis. Lancet 2011;377:1331-1340.

71 Flenady V, Middleton P, Smith GC, Duke W, Erwich JJ, Khong TY, Neilson J, Ezzati M, Koopmans L, Ellwood D, Fretts R, Frøen JF: Lancet's Stillbirths Series steering committee. Stillbirths: the way forward in high-income countries. Lancet 2011;377:1703-1717.

72 Pirkola J, Pouta A, Bloigu A, Hartikainen AL, Laitinen J, Järvelin MR, et al: Risks of overweight and abdominal obesity at age 16 years associated with prenatal exposures to maternal prepregnancy overweight and gestational diabetes mellitus. Diabetes Care 2010;33: 1115-1121.

73 Whitaker RC, Wright JA, Pepe MS, Seidel $\mathrm{KD}$, Dietz WH: Predicting obesity in young adulthood from childhood and parental obesity. N Engl J Med 1997;37:869-873.

74 Ong KK: Size at birth, postnatal growth and risk of obesity. Horm Res 2006;65 Suppl 3: 65-69.

75 Eriksson J, Forsen T, Osmond C, Barker D: Obesity from cradle to grave. Int J Obes Relat Metab Disord 2003;27:722-727.

-76 Baird J, Fisher D, Lucas P, Kleijnen J, Roberts $\mathrm{H}$, Law C: Being big or growing fast: systematic review of size and growth in infancy and later obesity. Br Med J 2005;331:929.

77 Krakowiak P, Walker CK, Bremer AA, Baker AS, Ozonoff S, Hansen RL, Hertz-Picciotto I: Maternal metabolic conditions and risk for autism and other neurodevelopmental disorders. Pediatrics 2012;129:e1121-e1128.

-78 Sheiner E, Levy A, Silverberg D, Menes TS Levy I, Katz M: Pregnancy after bariatric surgery is not associated with adverse perinatal outcome. Am J Obstet Gynecol 2004;190: 1335-1340

79 Maggard MA, Yermilov I, Li Z, Maglione M, Newberry S, Suttorp M: Pregnancy and fertility following bariatric surgery: a systematic review. JAMA 2008;300:2286-2296.

80 Sheiner E, Willis K, Yogev Y: Bariatric surgery: impact on pregnancy outcomes. Curr Diab Rep 2013;13:19-26.
Impact of Maternal Obesity on Fetal Health
Fetal Diagn Ther 2013;34:1-7 DOI: $10.1159 / 000350170$ 